\title{
Does Higher Inflation Lead to More Uncertain Inflation?
}

\section{A. Steven Holland}

I "stagflation," a period of high and rising inflation and unemployment. Over this time, higher inflation increasingly has come to be blamed for higher unemployment and reduced growth of real output. This contrasts sharply with previously held notions that there was either a long-run tradeoff between inflation and unemployment or a "natural rate of unemploy" ment" regardless of the inflation rate.

One reason why many people have changed their minds about inflation's impact on the economy is the presumed impact of "inflation uncertainty." Many now argue that there is greater uncertainty about future prices during periods of higher inflation. ${ }^{1}$ This increased uncertainty leads to a less efficient allocation of resources.

The best-known statement of this view came from Milton Friedman in his Nobel Lecture. Briefly stated, Friedman argued that greater inflation uncertainty shortens the average duration of contracts and reduces the efficiency of the price system. These two forces combine to lower the growth rate of real output and potentially increase the rate of unemployment. ${ }^{2}$

A. Steven Holland is an economist at the Federal Reserve Bank of St. Louis. Jude L. Naes, Ir., provided research assistance.

'Some have suggested that uncertainty begins to increase once the rate of inflation rises above some threshold. For example, see Logue and Willett (1976) and Hafer and Heyne-Hafer (1981).

${ }^{2}$ Friedman (1977). He suggests that the natural rate hypothesis holds for the very long run (a period of decades), because the economy's institutional structure for dealing with inflation eventually will adjust to eliminate the real effects of inftation.
Thus, if reducing inflation produces sufficiently larger output growth and lower unemployment in the long run, it is a worthwhile venture, even if doing so would produce a large short-term loss of output and rise in unemployment. ${ }^{3}$ While Friedman's discussion primarily concerns the variability of inflation - not necessarily identical to the notion of inflation uncertainty - it is clear that he considers them to be closely related.

This argument can be split into three separate hypotheses: (1) higher inflation leads to greater variability of inflation; (2) greater inflation variability implies greater uncertainty about future inflation; and (3) greater inflation uncertainty has a detrimental effect on economic activity. For policymakers to be concerned about the relevance of hypothesis 3 , they must believe that they can influence the level of inflation uncertainty. Hypotheses 1 and 2 state that they can do this by controlling the rate of inflation. If exogenous factors, such as energy shocks, are primarily responsible for greater inflation uncertainty, then policymakers can do little to affect it.

This article focuses on the validity of the first two hypotheses, which together imply that higher inflation leads to greater inflation uncertainty. Besides analyzing the causes of inflation uncertainty, an assessment of its potential effects is presented as well.

\footnotetext{
${ }^{3}$ To determine whether the long-term benefits of anti-inflation policies would offset the short-term costs, one must consider the timing of the output effects and the rate at which future output gains are discounted. See Meyer and Rasche (1980).
} 
Since energy shocks have been the single most important factor accounting for temporary price level changes, this article also investigates the impact of changes in the relative price of energy on both the rate of inflation and the level of inflation uncertainty. ${ }^{4}$ Energy shocks and inflation uncertainty should be positively associated, because the magnitude and timing of the effects of an energy shock on the rate of inflation are bound to be viewed with uncertainty.

\section{WHAT IS INELATION UNCEPTAINTV?}

Inflation uncertainty arises from a lack of complete knowledge about how future price levels are determined. Of course, an individual typically will have enough information to make some forecast of future inflation rates. A given estimate of next period's inflation can be thought of as the mean of some underlying probability distribution.

The forecaster's inflation uncertainty may be estimated by looking at the size of some specified confidence interval for his forecast. For example, a person may have predicted at the end of 1982 that 1983 infla tion had a 90 percent probability of being between 3 percent and 5 percent. If the same individual's 90 percent confidence interval for 1984 inflation (forecast at the end of 1983 ) is wider, say 4 percent to 7 percent, then his uncertainty about 1984 inflation is greater than it was for 1983 inflation.

The analysis presented here deals with inflation uncertainty for a representative individual. Though the level of an individual's uncertainty about inflation is not directly observable, ways of estimating it have been suggested in the literature. One of these is to use the variance or standard deviation of the errors made in forecasting inflation. A forecaster is trying to predict the outcome of a process that has both systematic and random components. With an unbiased forecast of the inflation rate, the variance of the forecast errors indicates the importance of the random component and can be considered an estimate of the level of inflation uncertainty. ${ }^{5}$ An implicit assumption in this type of analysis is that the variance need not be constant but may vary over time.

\footnotetext{
${ }^{4}$ See Tatom (1981).

IIt is the ex ante, not the ex post, varance of forecast errors that is relevant. Estimates of the latter, however, are commonly used as proxies for inflation uncertainty. See, for example, Klein (1978), Engle (1983), and Pagan, Hall and Trivedi (1983).
}

\section{WHY DOES TNRLATION UNCERTAINTY MATTER?}

The real effects of inflation uncertainty arise in part because inflation expectations enter into the contracting process. Any contract that provides for payment in nominal rather than real terms incorporates an expectation of future inflation. If actual inflation ends up higher than was expected when the contract was made $_{i}$ a redistribution of wealth occurs: those making the contracted nominal payments gain and those receiving them lose. If actual inflation is lower than was expected, the opposite wealth redistribution occurs.

When there is greater inflation uncertainty, riskaverse individuals will attempt to shorten the duration of contracts to reduce the risk of loss caused by deviations of actual from expected inflation. More frequent negotiation of contracts will divert economic resources to the contracting process from other, previously more efficient uses. ${ }^{\dot{B}}$

As the accompanying insert demonstrates, greater inflation uncertainty increases the risk associated with both saving and investing, since both require a contract of some kind. Individuals faced with greater inflation uncertainty may choose to reduce both their planned savings and investment. The result is likely to be lower long-term real economic growth.

Another potential real effect of inflation uncertainty is reduced efficiency of the price system in allocating resources. The basic idea is this: the more uncertain is inflation, "the harder it becomes to extract the signal about relative prices from the absolute prices." $\mathrm{Be}$ cause individual prices adjust to unexpected inflation at different rates due to the presence of long-term contracts and the costs of adjusting prices, relative prices may be temporarily distorted. ${ }^{8}$ They also may be incorrectly perceived, because information does not flow smoothly across markets. As a result, economic efficiency is reduced, producing lower output growth

\footnotetext{
Indexation of contracts can reduce (though not totally eliminate) the risk associated with contracting, and one would expect indexation to increase as inflation uncertainty increases. For a theoretical analysis of indexation in this context, see Gray (1978). Kein finds evidence that an increase in "long-term price uncertainty" leads to a reduction in the average term to maturity of outstanding corporate debt.

${ }^{7}$ Friedman, p. 467. Again, Friedman's discussion is in terms of inflaton variability; if this variability were anticipated, however, adjustments could be made that reduce or eliminate this effect. His discussion of this effect is based on the work of Hayek (1945) and Lucas (1973) among others.

${ }^{3}$ See Bordo (1980) and Sheshinskj and Weiss (1977),
} 


\section{How Inflation Uncertainty Creates Greater Risk for Savers and Investors}

To see how greater nillation uncertainty aftects savings and investment, consider the consequences of an inexperted price level inerease for a Baver. The expected real rate of retum $t^{*} t$ on sanings can be written:

$11 \mathrm{r}=\mathrm{i}-\mathrm{p}^{2}$

Where i is the nommal rate of retan lassumed to be

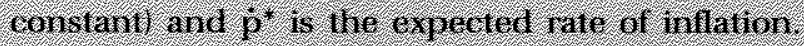
There is risk to the saver betcause the reatized real rate of refum in will only equal the expected real rate if the actuat inflation tate $\mathrm{W}$ e equals the expected inlation fare. The difference hetween the realized and expected real rites can be witten as:

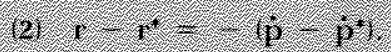

Using the variance of the difference hetween the aetial and expected ieal retum as a neasure of hisk and the variance ol milation forecast elrors as in estimate of inilation uriertainy. inflation incer: tainty ind risk are equated:

A simitar analysis car be carred ou ror other types or contiacts.

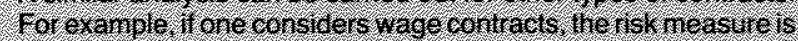
the variance of the adtual tess the oxpected real wagd

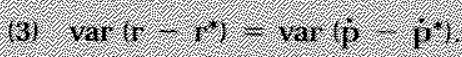

The effect of greater isk on the flow of savings is nat clear a primi. The greater risk could reduce the saving of risk averse individuals and as a conse Gience, tedtuge the aftula anount of investment as well. If a person's goal in saving is to assure a given level of real wealth in the fulure, however, greater irisk coild artually lead to nereased savings:

for investrient m physical capilat the andysis is not as straightforward because tho nominal rate of retum (t) varies to sonie degree with the rate of inflation. A deviation of actual from expected inta. fion does not necessarily indicate that the realized real rate is differem fiom the expected real rate of return. Therdore, the effet of intlation meerlainty: on investment risk depends on how the nominat rate of retim is experted to respond to a change in the rate of intation. This response may atso be liewed with uncertainy. If investors are risk averse, then risk-increasing inflion imeertanty will te: dire investiment and lower oufput growh in the long remin: and possibly higher unemployment than if all relative prices were corfectly perceived. ${ }^{9}$

The notion that greater inflation uncertainty leads to reduced economic growth and higher unemployment has been supported by empirical research. Mullineaux finds some measures of inflation uncertainty to have a negative effect on the growth of industrial production and a positive effect on unemployment; Levi and Makin get similar results for employment growth. Furthermore, Blejer and Liederman find that increased disper-

\footnotetext{
${ }^{9}$ Carlton (1981) discusses in detail the impact of inflation uncertainty on the organization of markets. He concludes that (p. 19):

in response to inflationary uncertainty, we expect to see fewer contracts with fixed prices for long time-periods, fewer customized goods, greater use of standardized goods sold in a liquid market, a move from outside contracting of customized goods to internal production through vertical integration, and a move from vertical integration to reliance on standard cuativy goods sotd in a lioutd market where "the marke" price is easy to observe. All of these changes are undesirabte from an efficiency standpoint.
}

sion of relative price changes leads to a significant reduction in real GNP and increased unemployment ${ }^{10}$

\section{WHY SHOULD MIGHER INFLATION LEAD TO GREATER INFLATION UNCERTAINTY?}

The relationship between higher rates of inflation and inflation uncertainty is based more on empirical regularities than on theoretical rationale. Beginning with Okun in 1971, several researchers have found that there are significant positive correlations between rates of inflation and the variability of inflation across countries and across time for a given country. Others

\footnotetext{
${ }^{10}$ See Mulineaux (1980), Levi and Makin (1980), and Blejer and Leiderman (1980). Evans (1983) finds an unstable price level to have a negative effect on real GNP growth, and Able (1980) finds a negative impact of inflation variability on the rate of investment.
} 
have found a positive relationship between inflation variability (or inflation itself) and proxies for inflation uncertainty, the latter including the dispersion of inflation expectations across survey respondents and the variance of estimated inflation forecast errors. The insert on pages 20 and 21 provides a summary of findings from previous studies.

The theoretical rationale centers on the hypothesis that a more inflationary economy produces greater uncertainty about the future direction of govemment policy, causing greater uncertainty about future inflation. Okun states that the application of fiscal and monetary policies is apt to be less consistent (i,e, predictable) during inflationary times because of the difficulty in reducing inflation without causing unacceptably high rates of unemployment and interest. ${ }^{11}$ In a similar vein, Friedman states that:

A burst of inflation produces strong pressure to counter it. Policy goes from one direction to the other, encouraging wide variation in the actual and anticipated rate of inflation. And, of course, in such an environment, no one has single-valued anticipations. Everyone recognizes that there is great uncertainty about what actual inflation will turn out to be over any specific future interval. ${ }^{12}$

One can argue that an inflationary economy creates an environment in which major policy changes become more likely and the effects of such policy changes become more uncertain. To support this argument, one need only look at some of the policy measures taken or proposed in recent years at least partially in response to an inflationary economy: deregulation of financial institutions, wage and price controls, indexation of income taxes and changes in methods for implementing monetary policy.

\section{NNFLATION FORECASTS AND THE VAPIANCE OF ETRORS}

The discussion above suggests that the variance of errors in forecasting inflation could be used as one measure of inflation uncertainty. If the variance of the forecast errors remains constant over time, so does the level of inflation uncertainty. One way to determine whether inflation uncertainty has changed over time is to test for non-constant valiance i.e., heteroscedasticityl in the residuals from a model of inflation expectations, ${ }^{13}$

\footnotetext{
"See Okun (1971).

${ }^{12}$ Friedman, p. 466 .

${ }^{13}$ This is the approach suggested by Engle (1982) and Pagan, Hall and Trived.
}

\section{Table 1}

Two Models of Inflation Expectations: III/1954-111/1983

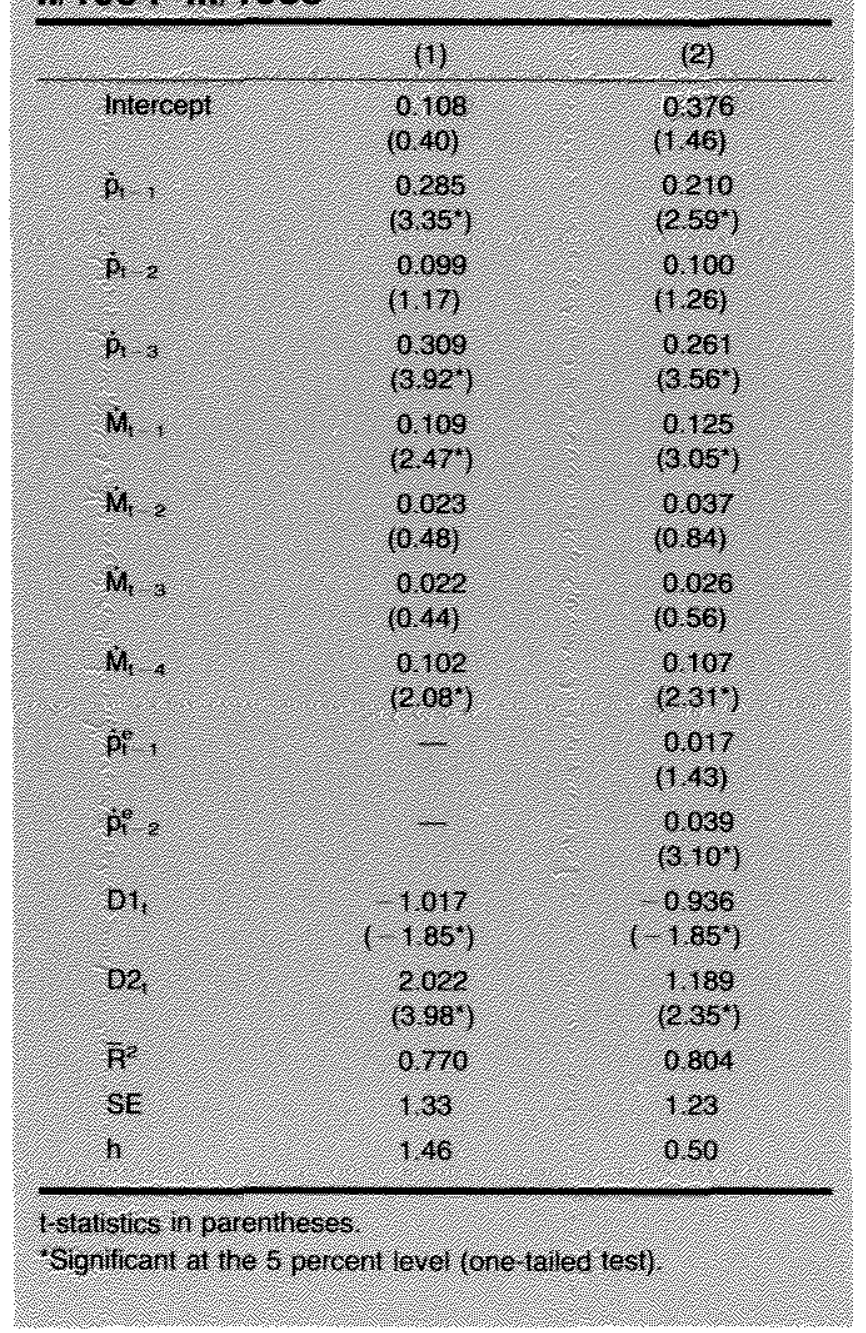

First, we need an inflation expectations model that provides unbiased forecasts over both lower and higher inflation periods; we can then test whether the error variance is larger for the higher inflation period. A model obtained by regressing the quarterly growth rate of the GNP deflator ( $p$ ) on its own lagged values, lagged values of the growth rate of $\mathrm{M} 1 \mathrm{M}$ ), and dummy variables for periods of wage-price controls and their aftermath (D1 and $\mathrm{D} 2$ ) is given by equation 1 in table $1 .^{14}$ The equation was estimated using data from 1//954-II/

\footnotetext{
"All growth rates are expressed in annualized tog differences. D has a unity value during the control period of $11 / 1971-1 / 1973$ and zero otherwise. D2 represents the period during which controls were being phased out, taking a unity value for the period $1 / 1973-1 / 1975$ and zero otherwise.
} 


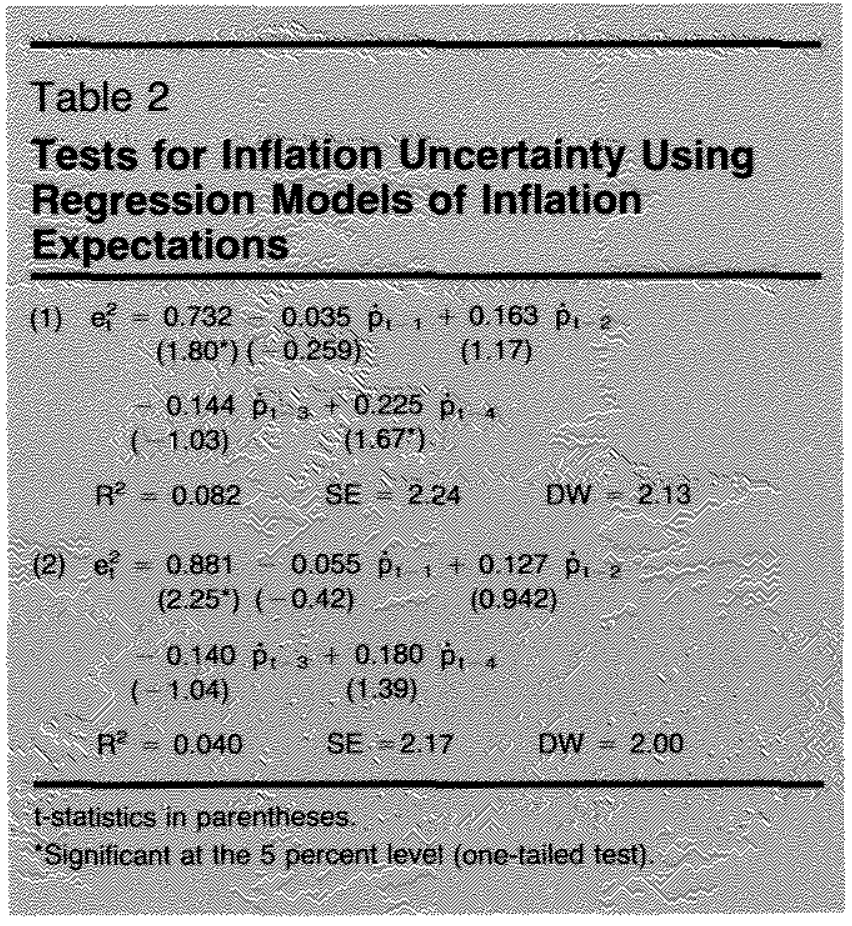

1983, and the number of lags was chosen using standard $t$ and $F$ tests. When we divide the sample into a lower inflation period, I//1954-IV/1967, and a higher inflation period, /1968-11//1983, we can reject the hypothesis that the error variance is the same in both periods. ${ }^{15}$ As expected, the variance is higher in the period of higher inflation, ${ }^{16}$

Another test of the constancy of the variance of the forecast enrors over time is obtained by regressing the squared value of the inflation forecast error for period $t$ $\left(e_{t}^{j}\right)$ estimated from equation 1 on the variables thought to cause changes in the variance. When four lagged values of the inflation rate are used, the estimated equation yields the results shown in equation 1 in table 2. The results indicate, once again, that inflation affects the variance of forecast errors using this model of ex-

${ }^{15}$ The average quarterly rate of growth of the GNP deflator between H/1954 and IV/1967 was 2.18 with a maximum of 4.57 and a minimum of $\cdots 0.87$; for $1 / 1968-11 / 1983$, the average growh rate of the GNP deflator was 6.31 with a maximum of 11.41 and a minimum of 2.83. The value of the calculated $F$-statistic $\left(\mathrm{F}_{53,47}=1.77\right)$ from the Goldfeld-Quand test is statistically significant at the 5 percent level. For an explenation of this test for heteroscedasticity, see Goldfeld and Quand (1965)

$16 \mathrm{~A}$ Chow test does not indicate that the structure of the model is different for the two periods. The Chow test statistic is $F_{10,98} \ldots$ 0.705 , far below the level required for statistical significance at the 5 percent level. pected inflation. ${ }^{17}$ The effect over four quarters is both positive (as indicated by the sum of the coefficients of the lagged values of the inflation rate $[0.209$ ) and statistically significant at the 5 percent level. ${ }^{18}$

\section{Relative Energy Price Changes and Expected Inflation}

The above result seems to suggest rather strongly that a higher inflation rate is associated with more inflation uncertainty. This conclusion must be carefully viewed, however; the results are quite sensitive to the way in which the model of inflation expectations is specified. In particular, if one considers the possibility that individuals anticipate some impact of a higher relative price of energy on the rate of inflation, then inflation does not affect the variance of the errors. An estimated inflation expectations model that incorporates two lagged values of the change in the relative price of energy is presented in equation 2 of lable $1^{19}$ When the sample was divided into the same lower and higher inflation periods as before land the impact of energy prices is taken into account), the hypothesis that the error variance is the same in both periods cannot be rejected at the 5 percent level of significance. ${ }^{20}$

Furthermore, as equation 2 in table 2 shows, lagged values of the inflation rate do not affect the squared inflation forecast error estimated from equation 2 in table $1 .^{21}$ Therefore, when this inflation expectations model is used, there is no indication that higher inflation is associated with greater inflation uncertainty.

\footnotetext{
${ }^{17}$ The test statistic $T^{2}$ (where $T$ is the number of observations) has a $x^{2}$ distribution with degrees of freedom equal to $T$ minus the number of regressors. This statistic is used to test for heteroscedasticity. In equation 1 in table 2, $\mathrm{TR}^{2}=9.62$, which is statistically significant at the 5 percent level. This test is suggested by Engle (1982).

${ }^{18}$ The t-statistic for the surm of the coefficients is 2.59 . Additional lagged values of $p$ up to a total of 12 had no effect. Lagged values of the rate of inflation are used instead of the current rate, because the rate for period is not known at the time the forecast is made. This procedure of regressing squared residuals on a sel of variables as a test for heteroscedasticity is suggested by Breusch and Pagan (1979).

10The relative price of energy is defined as the ratio of the "fuels and related products and power" component of the producer price index (PPI) to the business sector deflator. See Tatom for a slightly different model of the inflation rate isself (rather than expected infiation:

${ }^{20}$ The Goldfeld $Q$ Quandi $F$-statistic is $F_{51.45}=1.47$

${ }^{21}$ Weither the value of $T R^{2}(4.72)$ nor the sum of the coefficients of lagged intation $(0.112, t=1.44$ ) are statistically significant at the 5 percent level.
} 


\section{Previous Research on the Relationships among Inflation Rates, Inflation Variability and "Inflation Uncertainty"}

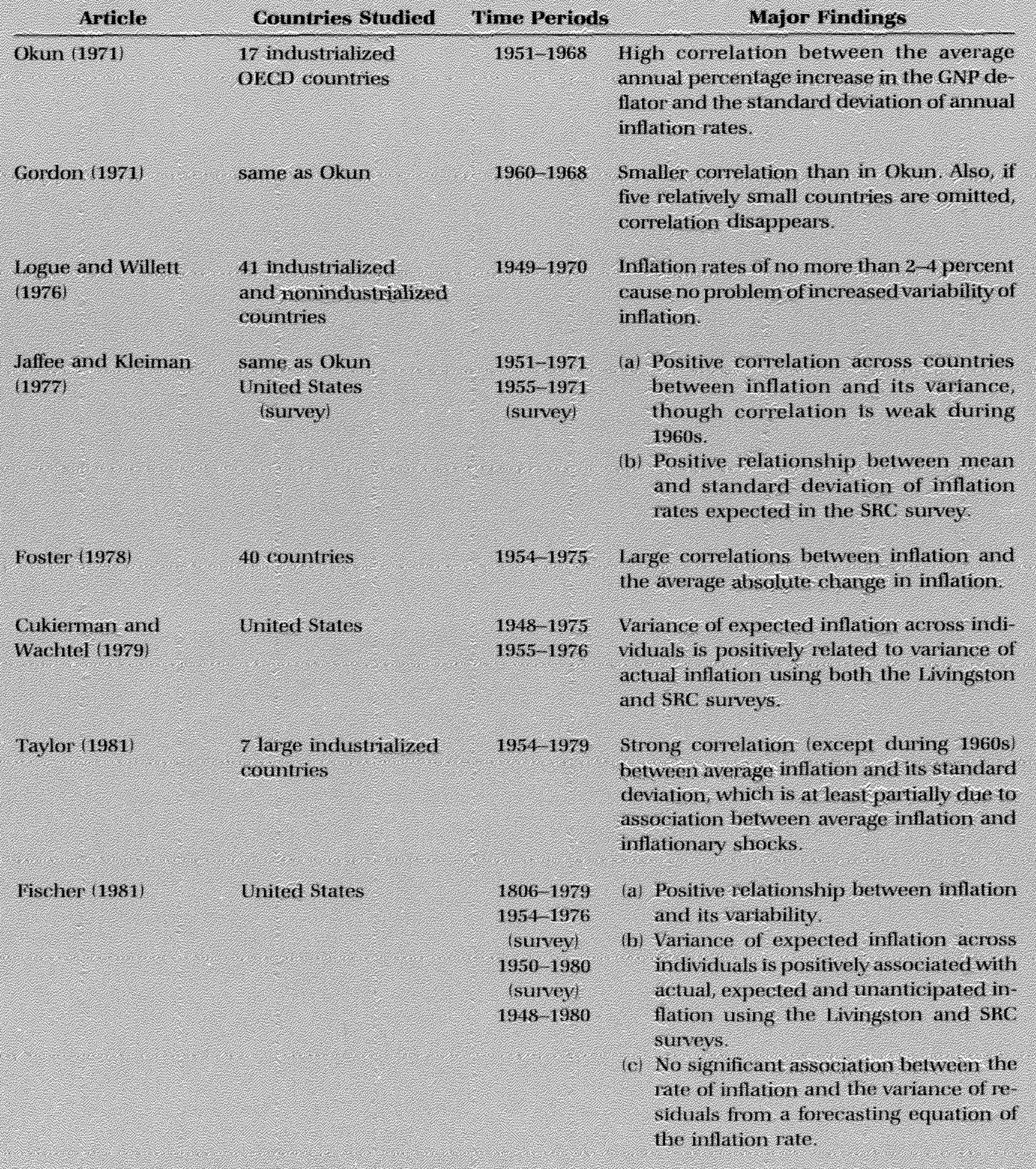




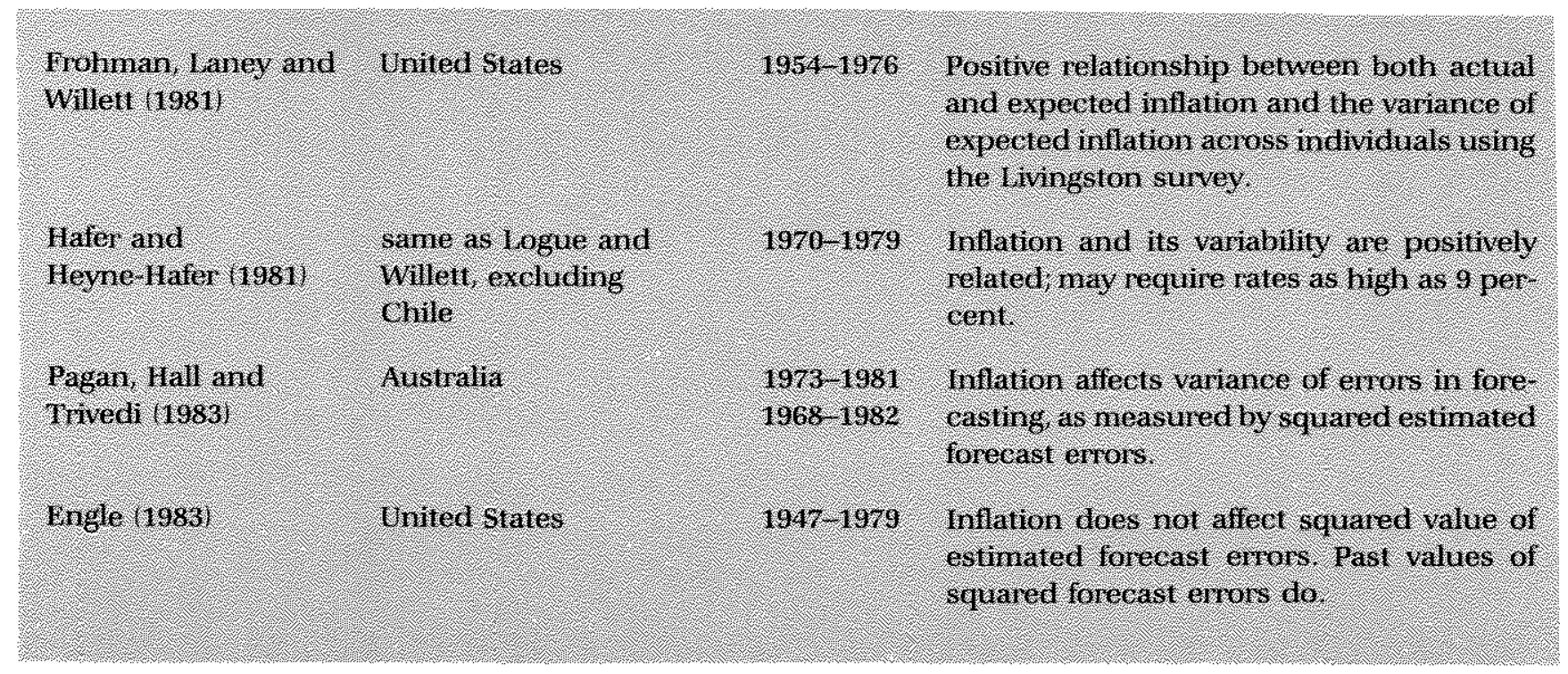

\section{INDIVIDUAL INFLATTION \\ UNCERTAINTY AND THE VARIABILITY OF INFLATION EXPECTATIONS AMONG INDIVIDUALS}

The preceding tests illustrate one of the major problems involved in trying to estimate an individual's uncertainty about future inflation: estimates can be sensitive to one's assumptions about the nature of the information used to forecast inflation. In this section, we use a different approach to estimating inflation uncertainty based on very different assumptions about the way individuals form inflation expectations.

In contrast to the models of inflation expectations estimated previously, individuals may use considerably more information to forecast inflation rates than the past growth rates of such aggregates as the price level and money supply. For example, each forecaster may have personal information regarding the historical relationship between the price of a specific product and the general price level. This specialized information is likely to be too costly for all individuals to obtain. If there is greater heterogeneity in the inflation signals that forecasters receive from this type of marketspecific information, then greater dispersion of individual inflation forecasts can result. An individual who observes a wider variety of predictions of next period's inflation rate through published sources, for example) may become more uncertain about the accuracy of his own forecast, especially if he believes that different forecasts are based on information he does not have. ${ }^{22}$

\footnotetext{
${ }^{22}$ This kind of partial information framework is used by Cukierman and Wachtel (1982). There is, however, an alternative explanation for
}

In the analysis to follow, it is assumed that greater dispersion of inflation forecasts among individuals leads to increased inflation uncertainty. Therefore, we use measures based on the variability of responses to the Livingston survey of inflation expectations to further investigate the relationship between inflation and inflation uncertainty. ${ }^{23}$

The standard deviation of the individual inflation forecasts from the Livingston survey is the first proxy for inflation uncertainty. Chart 1 shows the actual inflation rate over the forecast period and the mean and standard deviation of six-month inflation forecasts from the first half of 1954 to the first half of 1983 . The shaded areas of the chart represent periods of energy shocks. ${ }^{24}$ The chart indicates that both energy shocks

increased variability of individual inflation forecasts: forecasters may all use the same information but in different ways. This would not necessarily imply greater inflation uncertainty for a particular individual since each forecaster could be just as certain as he ever was about the accuracy of his forecast.

${ }^{23}$ Joseph Livingston of The Philadelphia Inquirer conducts a survey each spring and fall, requesting respondents to indicate their predictions about a number of economic indicators including the consumer price index (CP). Because the survey results published, for example, in June contain predictions for the following December, Livingston refers to them as six-month-ahead forecasts as does this article. (The survey also includes 12 -month forecasts, which are not used here.) Because the respondents to the June survey are thought to know only the April $\mathrm{CPl}$, however, they are actually predicting an eight-month rate of change. For a detailed discussion of the Livingston expectations data, see Carlson (1977). This article uses the data in Carlson's revised form updated to the present.

${ }^{24}$ The periods of energy shocks are the first half of 1973 to the second haif of 1974 , and the first half of 1979 to the first half of 1981. The quarterly deflator for fuels and related products and power civided by the business sector deflator grew at an annual rate of 22.9 percent from $\mathrm{V} / 1972$ to $\mathrm{V} / 1974$ and 23.4 percent from $\mathrm{l} / 1979$ to II/1981. 


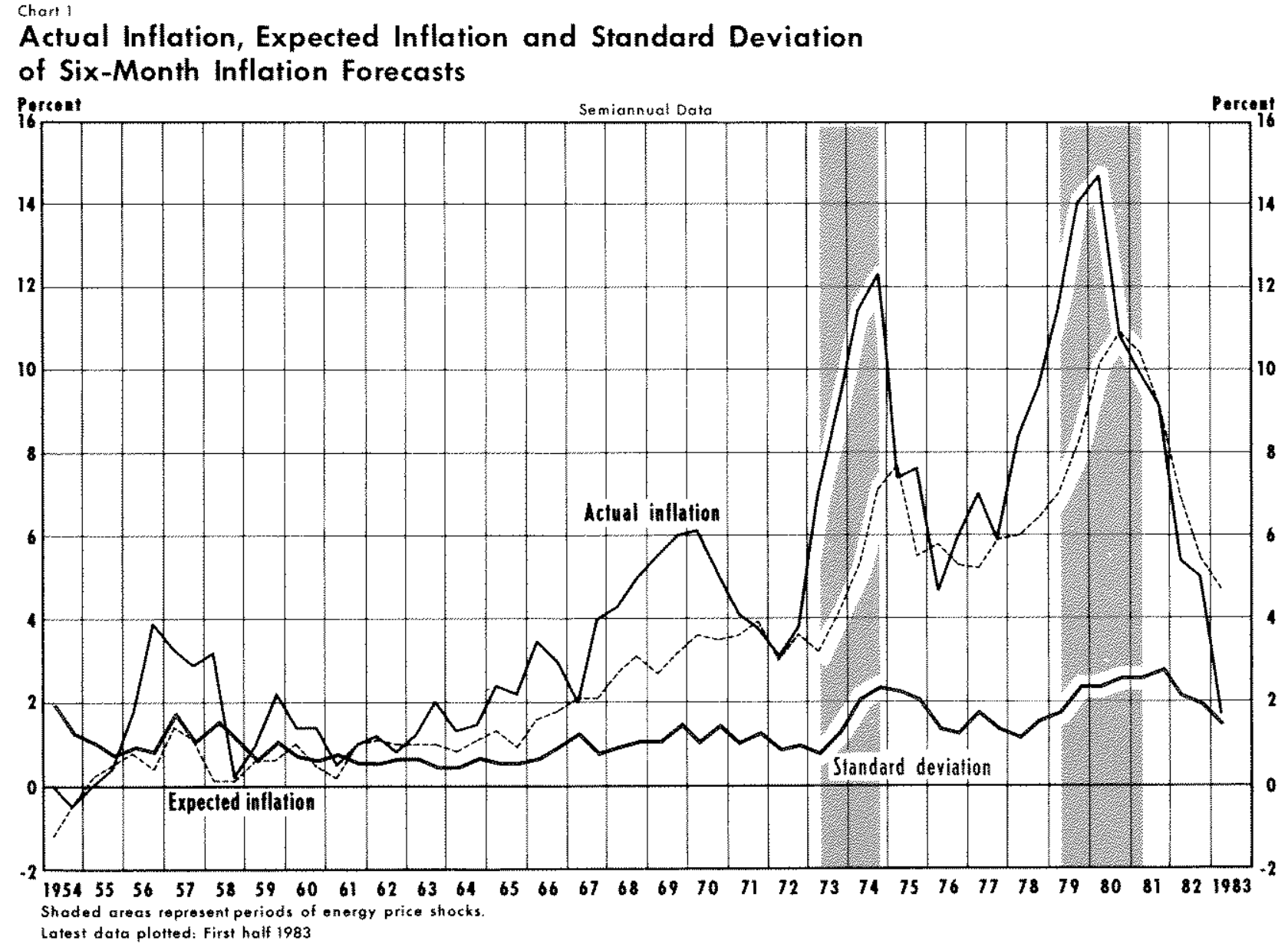

and inflation may have a positive impact on inflation uncertainty. All three series rose substantially during periods of energy shocks, and there are significant positive correlations between the uncertainty measure and the other two series in other periods. ${ }^{25}$

The root-mean-squared error (RMSE) of the individual forecasts of inflation from the survey serves as the second proxy for inflation uncertainty. An examination of chart 1 indicates that the survey mean inflation expectation is biased; it consistently underpredicts the inflation rate over most of the sample period. The RMSE of the inflation forecasts incorpo-

${ }^{25}$ The correlation coefficient between the standard deviation and the expected inflation rate is 0.787 for the entire period and 0.667 for the period omitting the two energy shock periods. Between the standard deviation and the actual intlation rate, the correlations are 0.724 and 0.597 , respectively. These figures are all statistically significant at the 5 percent leve: rates these errors. The squared value of this variable is the sum of the variance of inflation expectations across survey respondents (the standard deviation squared) and the squared forecast error using the survey mean as the expected inflation rate. ${ }^{26}$ The use of this variable

\footnotetext{
${ }^{20}$ The mean-squared error of the forecasts can be written:

$$
\begin{aligned}
& \text { MSE }_{\mathrm{i}}=\frac{1}{n} \underset{i \neq 1}{\mathrm{n}}\left(\dot{\mathrm{p}}_{\mathrm{i}}^{*}-\dot{\mathrm{p}}_{\mathrm{i}}\right)^{2}
\end{aligned}
$$

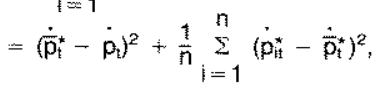

where $n$ is the number of forecasters, $\dot{p}_{i}^{*}$ is the expected rate of inflation for the ith forecaster, and $\dot{\bar{p}}^{\star}$ is the mean expected inftation tate among the forecasters. The first term on the tight-hand side of the equation is the squared forecast error, and the second is the variance of individual inflation expectations. We use the square root of this variable and the standard deviation of expectations because regressions using the mean-squared error and the variance exhibited heteroscedasticty.
} 
Chant 2

\section{Actual Inflation, Expected Inflation and Root-Mean-Squared Error} of Six-Month Inflation Forecasts

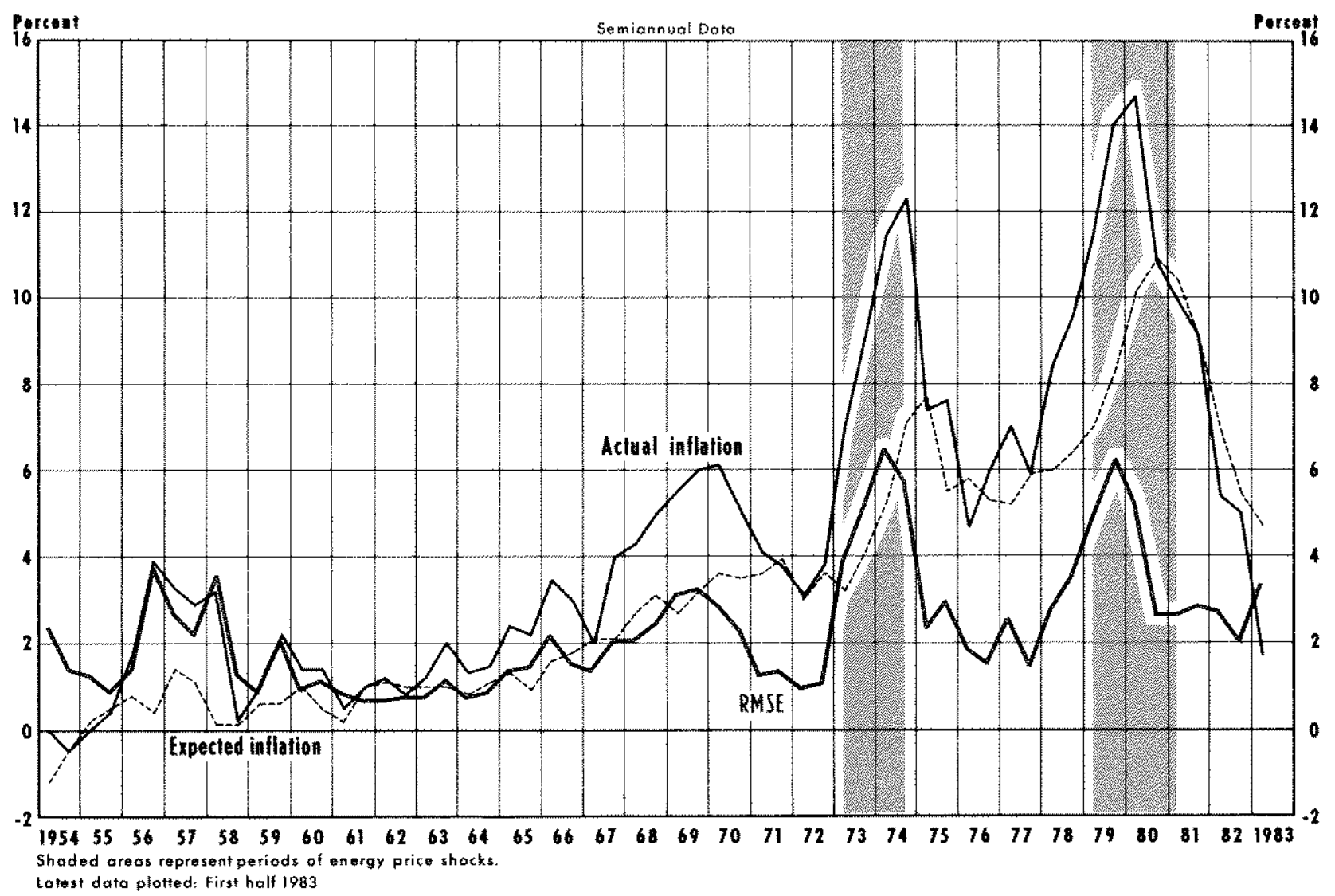

as a measure of inflation uncertainty assumes that there is greater inflation uncertainty, holding constant the variance of inflation expectations, when a large mean forecast error occurs than when a small mean forecast error is observed ${ }^{27}$

Chart 2 plots the RMSE along with the actual inflation rate and the mean expected inflation rate from the survey. Again there is a positive association between the uncertainty measure and the other two series, with the largest increases in RMSE occurring during periods of energy shocks. ${ }^{28}$ As chart 2 shows, the RMSE is

\footnotetext{
27The standard deviation of the forecasts has one advantage over RMSE as a proxy for inflation uncertainty: it does not contain any ex post information. RMSE $E_{t+1}$ includes the actual inflation rate from period $\mathrm{t}+\mathrm{t}, \dot{\mathrm{p}}_{\mathrm{z}+1}$.

${ }^{29}$ The correlation coefficient between RMSE and the expected infla tion rate 0.559 for the entire sample period and 0.433 for the period exclusive of the periods of energy shocks. Between RMSE and the actual rate of inflation, the correlations are 0.826 and 0.658 respectively.
}

considerably more variable than the standard deviation over the sample period. The most interesting difference in the two series, however, is their behavior during the energy shock periods: the standard deviation remains higher than normal throughout each of the energy shock periods and does not decline until the period is over; the RMSE peaks, then declines substantially while relative energy prices are still rising Therefore, these two measures imply different responses of inflation uncertainty to energy shocks.

\section{INFLATION AND THE VATIABHLITY OF INELATION FOREGASTS}

This section provides more detailed evidence on the effects of inflation and energy shocks on the two measures of inflation uncertainty discussed above. Table 3 presents results from regressions based on six-month inflation forecasts. The data used are from the same sample period shown in the charts. 


\section{Table 3}

\section{Tests for Inflation Uncentainty Using Livingston Survey Data}

\begin{tabular}{|c|c|c|}
\hline & 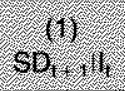 & $(1)(19)$ \\
\hline meresu & $\frac{0,002}{(6,32 x)}$ & $\left(\begin{array}{l}1,407 \\
(4,32)\end{array}\right.$ \\
\hline p. & $\left(\begin{array}{l}0.103 \\
(5.40 \%\end{array}\right.$ & $(0.267$ \\
\hline$p_{1}, x^{2}$ & S. & $\begin{array}{l}0.036 \\
(-0.57)\end{array}$ \\
\hline & 2. & $\frac{9.100}{(2.64)}$ \\
\hline p. & & 0.0223 \\
\hline Surn & & $\begin{array}{l}0.186 \\
(2.69)\end{array}$ \\
\hline pt. & & $(1.84)$ \\
\hline p & $(0,060$ & $(0.02)$ \\
\hline$p^{0}$ & $(0.008$ & $(7.024$ \\
\hline 10.2 & $(0.044)$ & 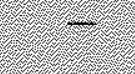 \\
\hline sum & 0.023 & $(0.01)$ \\
\hline I) & $(0.389)$ & $\begin{array}{r}0.448 \\
(3.85)\end{array}$ \\
\hline $\mathrm{r}^{2}$ & 0.769 & 0.668 \\
\hline SE & 0.00 & 0.84 \\
\hline $12 W$ & 205 & 1.91 \\
\hline
\end{tabular}

\section{Inflation's Effect on the Standard Deviation of Forecasts}

In equation 1 , the dependent variable is $\mathrm{SD}_{\mathrm{t}+1} \mathrm{I}_{\mathrm{t}}$, which is the standard deviation of inflation expectations for period $t+1$ as calculated from responses to the Livingston survey at period $t^{29}$ The most recent six-month rate of inflation known to the forecasters, $\dot{\mathrm{p}}_{\mathrm{t}}$ has a positive and strongly significant effect on the standard deviation of the forecasts. Lagged values of this variable had no significant effect. The value of the

${ }^{29}$ The variable is written $\mathrm{SD}_{\mathrm{t}+1} \mathrm{I}_{4}$ to indicate that it is based on forecasts of period $t+1$ inflation given an information set from period $t_{\mathrm{t}} \mathrm{t}_{\mathrm{t}}$. intercept implies that, in the absence of inflation or changes in the relative price of energy, the standard deviation of inflation forecasts would be about a 0.8 annualized percentage rate. The coefficient for $\dot{p}_{4}$ indicates that for every 1 percentage-point increase in the annual rate of inflation, the standard deviation increases by about 0.1 percentage point. Therefore, with 8 percent inflation, the standard deviation would be twice as high as with zero inflation.

The three most recent values of the annualized sixmonth change in the relative price of energy $\left(\dot{\boldsymbol{p}}^{\mathrm{e}}\right)$ also have a significant positive impact on this measure of inflation uncertainty ${ }^{30}$ A 1 percent increase in this variable leads to an increase in the standard deviation of 0.023 percentage points over three six-month periods. In other words, an energy shock affects this measure of inflation uncertainty for up to 18 months. A 20 percentage-point increase in the relative price of energy - not uncommon in the last decade - causes the standard deviation of inflation expectations to increase by about 0.45 percentage points. ${ }^{31}$

\section{Inflation's Effect on the Root-Mear-Squared Error of Forecasts}

Equation 2 presents results using the RMSE of inflation forecasts for period $t+1\left(\mathrm{RMSE}_{\mathrm{t}+1}\right)$ as the dependent variable ${ }^{32}$ The conclusion that inflation exerts a positive influence on inflation uncertainty is the same as in equation 1, although the impact occurs over four six-month periods. The sum of the coefficients of current and lagged inflation is positive and significant. Over 24 months, a 1 percentage-point increase in inflation leads to an increase in RMSE of about 0.19 percentage points. Although this is about twice the impact that

\footnotetext{
${ }^{30}$ The series tor the inffation rate and changes in the relative price of energy are constructed to include the most recent numbers known by the forecaster, so monthly data are used. The spring forecaster is assumed to know the April levels of the CPI and the relative price of energy, so the six-month rate of change is calculated between October and April. For the fall forecast, the rate is calculated between April and October. The denominator in the relative energy price variable for monthly data is the finished goods component of the PPI.

${ }^{31}$ The regressions also were run with a somewhat different dependent variable, the standatd deviation across individuals of the expected level of the CPI divided by the mean expected level. This is the coefficient of variation of the CPI level forecasts. The results were similar to those for the standard devation of the inflation rate forecasts. The coefficient of variation of the inflation rate forecasts is clearly an inappropriate variable to use, since, as the expected inflation rate approaches zero, the coefficient of variation approaches infinity.

${ }^{32}$ RMSE $_{t+1}=\sqrt{\left(S D_{t+1} I_{t}\right)^{2}+\left(\dot{\bar{p}}_{t+1}^{*} I_{t}-\dot{\mathrm{p}}_{\mathrm{t}+1}\right)^{2}}$.
} 
inflation had on the standard deviation, the constant term is nearly twice as high in this equation thus, the impacts actually are quite similar. The initial impact of inflation on RMSE is much greater than it is on the standard deviation, but this effect is partially offset after 24 months have passed.

The impact of relative energy price changes is quite different in this regression than it was in equation 1. The initial impact on the uncertainty measure is positive, but the effect is totally offset 12 months later. ${ }^{33}$ Consequently, if the relative price of energy were to increase by the same amount each period, it would cease to have any effect on the RMSE after 12 months. In contrast, for the standard deviation of expectations to stabilize, the level rather than the growth rate of the relative price of energy must stabilize. ${ }^{34}$

In both equations, the effect of higher inflation on the measure of inflation uncertainty is positive and permanent. There is no indication that, over time, forecasters come to be just as certain about higher rates of inflation as they were about lower rates. This evidence supports the hypothesis that higher inflation leads to more uncertain inflation.

\section{CONCLUSION}

Researchers have compiled considerable evidence suggesting that the rate and variability of inflation are positively related and a lesser amount of evidence link ing these variables to inflation uncertainty. This article has explored the relationship between the rate of inflation and the level of inflation uncertainty in greater detail, looking also at the impact of energy shocks on inflation uncertainty.

The empirical results presented here are somewhat mixed and are sensitive to the method chosen for measuring inflation uncertainty. On the one hand, a model of inflation expectations was introduced and estimated for which the variance of the estimated inflafion forecast errors is related to the rate of inflation. A

\footnotetext{
${ }^{33}$ The inclusion of the variable $\hat{p}_{t+1}^{e}$ in the regression is not meant to imply that forecasters know the value of this variable, only that it affects RMSE $_{\mathrm{t}+1}$.

34 The regressions in table 3 also were run with several other independent variables, none of which was statistically significant at the 5 percent level. These included current and lagged values of the absolute value of unanticipated inflation (based on the survey mean expectation), a dummy variable for the period of wage and price controls, and a time trend. In regressions excluding the relative price of energy, the estimated effects of inflation on the uncertainty measures were somewhat larger.
}

different inflation expectations model - one incorporating the effects of changes in the relative price of energy on expected inflation m- led to the opposite conclusion. On the other hand, there are positive relationships between the rate of inflation and the standard deviation and root-mean-squared error of infla tion forecasts taken from the Livingston survey. Energy shocks also affect these two measures of inflation uncertainty, but in quite different ways.

Because the results of empirical tests based on inflation forecasting models are sensitive to the specificafion of the model the usefuness of these results is questionable. Therefore, uncertainty measures based on the variability of "observed" inflation forecasts or forecast errors should be given more attention. In this article, these measures indicate that inflation uncertainty can be reduced if the rate of inflation is reduced.

In light of recent evidence that greater inflation uncertainty has a detrimental effect on the levels of economic activity and unemployment, the reduction of inflation uncertainty is an important potential benefit of anti-inflation policies.

\section{REFERENCES}

Able, Stephen L. "Inflation Uncertainty, Investment Spending, and Fiscal Policy," Federal Reserve Bank of Kansas City Economic Review (February 1980), pp. 3-13.

Blejer, Mario I., and Leonardo Liederman. "On the Real Effects of Inflation and Relative-Price Variability: Some Empirical Evidence," Review of Economics and Statistics (November 1980), pp. 539 44.

Bordo, Michael David. "The Effects of Monetary Change on Relative Commodity Prices and the Role of Long-Term Contracts," Journal of Political Economy (December 1980), pp. 1088-1109.

Breusch, T. S., and A. R. Pagan. "A Simple Test for Heteroscedasticity and Random Coefficient Variation," Econometrica (September 1979), pp. 1287-94.

Carlson, John A. "A Study of Price Forecasts," Annals of Economic and Social Measurement (Winter 1977), pp. 27-56.

Carlton, Dennis W. "The Disruptive Effect of Intlation on the Orga" nization of Markets," National Bureau of Economic Research, Conterence Paper No. 104 (1981).

Cukierman, Alex, and Paul Wachtel. "Differential fntlationary Expectations and the Variability of the Rate of Inflation: Theory and Evidence," American Economic Review (September 1979), pp. $595-609$

"Relative Price Variability and Nonuniform Inflationary Expectations," Journal of Political Economy (February 1982), pp. 146-57.

Engle, Robert F. "Autoregressive Conditional Heteroscedasticity With Estimates of the Variance of United Kingdom Inflation," Econometrica (July 1982), pp. 987-1007. 
"Estimates of the Variance of U.S. Inflation Based upon the ARCH Model," Journal of Money, Credit and Banking (August 1983), pp. 286-301.

Evans, Paul. "Price-Level Instability and Output in the U.S.," Economic Inquiry (April 1983), pp. 172-87.

Fischer, Stanley. "Towards an Understanding of the Costs of Infla. tion: II, "in Karl Brunner and Allan $\mathrm{H}$. Meltzer, eds., The Costs and Consequences of Inflation, Carnegie-Rochester Conference Series on Public Policy (Autumn 1981), pp. 5-41.

Foster, Edward. "The Variability of Inflation," Review of Economics and Statistics (August 1978), pp. 346-50.

Friedman, Milton. "Nobel Lecture: Inflation and Unemployment," Journal of Political Economy (June 1977), pp. 451-72.

Frohman, Deborah A., Leroy O. Laney and Thomas D. Willett. "Uncertainty Costs of High Inflation," Voice of the Federal Reserve Bank of Dallas (July 1981), pp. 1-9.

Goldfead, Stephen M, and Richard E. Quandt. "Some Tests for Homoscedasticity," Joumal of the American Statistical Association (June 1965), pp. 539-47.

Gofdon, Robert J. "Steady Anticipated Inflation: Mirage or Oasis?" Brookings Papers on Economic Activity (2:1971), pp. 499-510.

Gray, Jo Anna. "On Indexation and Contract Length," Journal of Polfical Economy (February 1978), pp. 1-18.

Hafer, R. W, and Gail Heyne-Hafer. "The Relationship between Intlation and lis Variability: International Evidence from the 1970s," Journal of Macroeconomics (Fall 1981), pp. 571-77.

Hayek, F. A. "The Use of Knowledge in Society," American Eco. nomic Review (September 1945), pp. 519-30.

Jaffee, Dwight, and Ephraim Kleiman. "The Welfare Implications of Uneven Inflation," in Erik Lundberg, ed., Inftation Theory and Antiinflation Policy (Westview Press, 1977), pp. 285-307.
Klein, Benjamin. "The Measurement of Long- and Short-Term Price Uncertainty: A Moving Regression Time Series Analysis," Economic inquiry (july 1978), pp. 438-52.

Levi, Maurice D., and John H. Makin. "Inflation Uncertainty and the Phillps Curve: Some Empirical Evidence," American Economic Review (December 1980), pp. 1022-27.

Logue, Dennis $\mathrm{E}_{\text {., }}$ and Thomas D. Willett. "A Note on the Relation between the Rate and Variability of inflation," Economica (May 1976). pp. 151-58.

Lucas, Robert E., Jr. "Some International Evidence on OutputInflation Tradeoffs," American Economic Review (June 1973), pp. 326-34.

Meyer, Laurence H., and Robert H. Rasche. "On the Costs and Benefits of Antiminflation Policies ${ }_{\mathrm{s}}^{\text {"t }}$ this Review, (February 1980), pp. 3-14.

Mullineaux Donald J. "Unemployment, Industrial Production, and Inflation Uncertainty in the United States," Review of Economics and Statistics (May 1980), pp. 163-69.

Okun, Arthur M. "The Mirage of Steady Inflation," Brookings Papers on Economic Activity (2:1971), pp. 485-98.

Pagan, A. R., A. D. Hall and P. K. Trivedi. "Assessing the Variability of Inflation:" Review of Economic Studies (October 1983), pp. $585-96$.

Sheshinski, Eytan and Yoram Weiss. "Inflation and Costs of Price Adjustment," Review of Economic Studies (June 1977), pp. 287m 303.

Tatom, John A. "Energy Prices and Short-Run Economic Performance," this Review (January 1981), pp. 3-17.

Taylor, John B. "On the Relation Between the Variability of Inflation and the Average Inflation Rate, "in The Costs and Consequences of Inflation, pp. 57-85. See Fischer. 